\title{
Designing, Implementation and Evaluation of an E- portfolio for Assessment of Surgical Technologist Students in Iran: a Mixed Method Study
}

\section{Leila Sadati}

Alborz University of Medical Sciences

\section{Sahar Karami}

Tehran University Of Medical Sciences

Rana Abjar

Alborz University of Medical Sciences

Mehdi Tayebi-Arasteh

Alborz University Of Medical Sciences

Fatemeh Edalat

Islamic Azad University

pourya kanani

shahid beheshti university of medical sciences

Zahra Nouri khaneghah ( $\nabla$ z_noori86@yahoo.com )

Iran University Of Medical Sciences

\section{Research Article}

Keywords: Electronic portfolio, Clinical education, Reflection, Surgical technologist

Posted Date: September 27th, 2021

DOl: https://doi.org/10.21203/rs.3.rs-801093/v1

License: (9) This work is licensed under a Creative Commons Attribution 4.0 International License.

Read Full License 


\section{Abstract}

Background: Building a portfolio is an appropriate method for assessing competency and practice in clinical settings. Portfolio assessment provides opportunities for students to reflect on their performance and therefore could have a critical role in observing students' progress and developing competencies. With the emphasis of modern medical education on e-portfolios, the present study was done to design, implement, and evaluate an electronic portfolio to assess surgical technologist students learning in Iran.

Methods: This mixed study was conducted in three stages: "designing," "implementation," and "evaluation." The "design" stage included a literature review, the completion and modification of the list of portfolio items, and content approval by experts. The "implementation" stage involved loading the system, holding workshops for students and clinical preceptors. Finally, the "evaluation" stage included assessing preceptors' and students' satisfaction, knowledge, and clinical skills and recording the number of reflections.

Results: The paired sample t-test result shows that students' knowledge and clinical skills significantly improved. More than two-thirds of the students and preceptors were thoroughly satisfied with the eportfolio assessment. On average, each student had more than three reflections recorded.

Conclusions: Using an e-portfolio assessment satisfies students and preceptors, improves surgical technologist students' knowledge and skills, and supports their progress toward achieving professional goals; therefore, it is recommended as a comprehensive and cost-effective assessment method.

\section{Background:}

Today, education of medical and paramedical students is mainly based on competency-based education (1). In competency-based education, there is an emphasis on educational consequences, professional practice, and assessment methods; therefore, diverse means of evaluation such as portfolios are proposed to appraise learners' competencies and practices (2). However, the term "Portfolio" first became popular in education in 1990 and was first defined as an organized complex of learnt subjects (3). It was broadly used in medical education over the last two decades to develop learners' competency (4). Today, portfolio is known as a tool for gathering and assessing information relevant to learners' development in appointed assignments and defined competencies $(2,5)$ and it is introduced as a competent method in motivating and guiding the learners towards reflection in assessment, Preceptors, by providing opportunities for reflection, assist students in not only developing their knowledge and skill but also in correcting their practice and acquiring competency $(6,7)$. Thus, the relation between the students' knowledge and practice is improved (8). Portfolios are available in two formats: paper and electronic. However, for a variety of reasons, including ease of access, prevention of excessive consumption of paper, and environmental concerns, electronic or network-based portfolios are becoming more popular (9). Electronic portfolio is a learning and assessment tool with features such as saving, reconsideration of data related to student's practice over a certain period of time and in a digital environment for a 
specific goal. It can present these documents and evidence to one or more audiences. In addition, it can provide benefits such as increasing motivation in students, sharing contents with evaluators and other students, hyperlinking the data, easily updating contents, easily accessing portfolios for both students and schools, reducing paper consumption, making students reconsider and finally students can recognize their strengths and weaknesses in their academic years $(10,11)$. However, there are flaws such as the requirement for an internet connection and computer skills as well as ethical challenges, which in some cases cause students and teacher to be reluctant to use this assessment system(12) Therefore, it is recommended that in addition to emphasizing the several benefits of this system of assessment on students' learning, this system be used mandatorily in medical science universities. Results show that despite the initial resistance against this system, after a while, learners use it in a much more active, autonomous and dynamic manner, and move towards self-learning with significant growth in critical thinking (13).

\section{Methods:}

This is a mixed method study, which was designed, implemented and assessed after approval of initial research project in the center for medical education research and development of Ministry of Health and Medical Education with license code No. 97006.

\section{Designing:}

The first step of this stage was to conduct a review in PubMed, Science Direct, Google scholar, SID, Scopus, Magiran databases between 1990 and 2019 with the keywords of clinical assessment, assessment tools, portfolio, e-portfolio, logbook and studies related to portfolio and e-portfolio were included in the study. Then, items considered in previous studies' portfolios were listed. In the second step, a meeting with the operating room board as an expert panel was held and the prepared list was corrected and completed in accordance with educational goals of the operating room curriculum. Then in the third step, a meeting was held with an expert working for Jame Tabib Electronic System Launching Company and the requested program was delivered to him in order to design and upload it in the eportfolio assessment system. The final content that approved for uploading included discipline regulations, study resources, training syllabus, logbook, educational objectives of the course, course activities, an interactional space for receiving feedbacks and providing reflection opportunities.

\section{Implementation:}

In this stage, the first step was to upload the e-portfolio assessment system, which included all of the features and contents of the research team (https://tabib.abzums.ac.ir). The second step was to hold seven educational workshops for preceptors and students to familiarize them with the system and its operation. These workshops were held with 7 preceptors and 56 students in eight groups. During the training classes, verbal informed consent was obtained from the participants. In the end of this stage, the system was used to assess of the students in the first semester of the 2020. 


\section{Evaluation:}

In order to evaluate the program, the Kirkpatrick model was used in two stages: reaction and learning (14). For this purpose, Ahmadi et al. survey was used to assess students' satisfaction (15). Also, a standard multiple-choice question (pre-posttest) and checklist compatible with the educational goals were used to assessment of students 'knowledge and skills. In addition, due to importance of reflection in the portfolio assessment, the number of reflections recorded by students was assessed as one the consequences of learning in different fields.

\section{Results:}

Participants of this study included 56 students and seven preceptors. Sixteen students (28.5\%) were male, while $40(71.5 \%)$ were female. The mean age of the students was $1.74 \pm 19.01$. The preceptors were all female, with a mean age of $1.37 \pm 38.96$.

Table 1: compares students' knowledge and skill scores and Table 2 :shows students and preceptors' satisfaction levels with the portfolio assessment .

The paired sample t-test results show that the knowledge and the practical skills of the students have significantly improved after the portfolio assessment.

Table 1

compares students' knowledge and practical skill scores before and after assessment

\begin{tabular}{|llll|}
\hline Variable & Mean & Standard deviation & \multirow{2}{*}{-value } \\
\hline Knowledge before the assessment & 4.29 & 1.58 & 0.011 \\
Knowledge after the assessment & 7.89 & 1.63 & \multirow{2}{*}{0.023} \\
Practical Skills before the assessment & 5.89 & 1.34 & \\
\cline { 1 - 3 } & &
\end{tabular}

Table 2

Frequency of students and preceptors' satisfactions with portfolio assessment

\begin{tabular}{|llll|}
\hline Variable & Frequency (\%) & & \\
\cline { 2 - 4 } & Completely Satisfied & Relatively Satisfied & Unsatisfied \\
\hline Students' Satisfaction & $40(71.42 \%)$ & $14(25 \%)$ & $2(3.58 \%)$ \\
\hline Preceptors' Satisfaction & $6(85.72 \%)$ & $1(14.28 \%)$ & $0(0)$ \\
\hline
\end{tabular}


Results show that more than two-thirds of the preceptors and the students were completely satisfied with the e-portfolio assessment. In an analysis of the survey's open-ended question (would you please explain the advantages and disadvantages of this method of assessment in comparison to other commonly used methods?), instances like resource management, the need for an internet infrastructure, access to information, improvement of interactions, organized assessment, learning combined with assessment, transparency of assessment and opportunities for reflections and independent learning were identified. An analysis of the number of recorded reflections shows that, on average, each student had more than three recorded reflections with preceptors' feedbacks during their 16 days of training. Forty-five percent of these recorded reflections were about surgery techniques, $33 \%$ were about surgery-related care, $12 \%$ were about observance of aseptic principles and sterilization and $10 \%$ were about surgical equipment.

\section{Discussion:}

The findings of this study indicate that e-portfolios have a positive impact on students' learning in cognitive and psychomotor areas, as both knowledge and clinical skills of students improved after this project was implemented. As a result, Lai C-Y et al. claimed that portfolios aided clinical learning through features such as self-awareness, self-assessment, and self-judgment (16). Furthermore, Vaghee et al. reported that e-portfolios improved students' academic achievement by involving students in the teaching-learning process (17). Brown demonstrated that portfolios improved students' learning and changed their perceptions of this profession (18). In other studies, portfolios enhanced learning during training in a women's ward (19) and enhanced both quality and the depth of learning in medical students (20). Gomez et al. investigated e-portfolios to assess quantitatively surgical skills. Seventy-nine percent of the students felt they had more access to their professors and at the end of each course, on average, students reached $65 \%$ of the defined general goals and $87 \%$ of skill goals (13). In another similar study, this tool increased clinical competency of nurses in all aspects (21). All of the preceding studies are consistent with this study's results. Therefore, it seems that this method can improve clinical skills by increasing interaction between the student and the preceptor, increasing feedbacks and encouraging students to reconsider.

Another outcome measured in this study was satisfaction of students and preceptors with the portfolio assessment. The results show that most of the students and preceptors were satisfied with the e-portfolio for assessment of clinical competency. Therefore, Asadi et al. preferred this method of assessment over other commonly used methods (22) and in other similar studies, students were more satisfied with the portfolio method than the other commonly used methods because this method focuses on students' progress and feedbacks from preceptors (20). According to Ahamdi et al., the total score of satisfaction with e-portfolio assessment was higher than the other common assessments (15). Contrary to these results, Tailor and colleagues believed $60 \%$ of medical interns was not beneficial with e-portfolios (10). Also, students in Gillian et al study were mostly dissatisfied and only $22 \%$ of them found e-portfolios useful (23). In another study, students reported low motivation and moderate self-confidence when it came to using e-portfolios (24). Different results can be due to initial anxiety in applying this method, incompletion of the prepared system content, unfamiliarity with the system and lack of a sufficient 
supervision. Gulden et al studied 90 e-portfolios and indicated that the received feedbacks were mostly limited to general opinions and lacked specific comments and recommendations for further actions and also no certain goals were defined for learners (25). Thus, considered items, preparedness of preceptors and learners, motivation for constant and correct use of this tool all impact its efficiency and students' satisfaction. Mi Yoo and colleagues believe that when evaluators with an appropriate education do the assessments based on certain standards and in a systematic way, the results are more valid (5). The last result, assessment of the number of recorded reflections, showed that, on average, each student had more than three reflection experiences with feedbacks from preceptors. Developing reflective skills is one of the unique features of portfolios that lead to improving clinical skills (26). During the implementation of this project, there was always an emphasis on reflection with the feedback from preceptors. $51.3 \%$ of students in a study reported that the reflection was helpful .other studies recommend that using eportfolios with feedbacks could help students in academic achievement (7).

\section{Conclusion:}

Regarding the positive impacts of this method of assessment on students' satisfaction, knowledge, and skills, it seems that applying an e-portfolio as one of the novel tools of assessment can be a proper replacement for the present assessment methods by providing opportunities for feedback and reflection. Therefore, this method is recommended in the clinical assessment of surgical technologist students.

\section{Abbreviations:}

e-portfolio: electronic portfolio

\section{Declarations:}

\section{Ethics approval and consent to participate}

This project has been accepted by the ethical committee of the Iran National Center for Strategic Research in Medical Education under ethical code \#97006. The authors confirm that all methods were performed in accordance with the relevant guidelines and regulations. Researchers obtained verbal informed consent from all participants after giving similar educational information to the participants in the training meetings about the study's objectives. Also, obtaining verbal consent from the participants was mentioned in the initial proposal of this research, and the ethics committee was aware of this.

\section{Consent for publication}

“Not applicable”

\section{Availability of data and material}


The datasets generated and analyzed during the current study are not publicly available because consent was not obtained from study participants for data to be made public. However, reasonable requests for the raw data will be answered by the first author (L. Sadati) or the corresponding author (Z. N. Khaneghah) subject to approval from ethical committee of Iran National Center for Strategic Research in Medical Education.

\section{Competing interests}

There has been no duplicate publication or submission elsewhere, and no ethical problem or conflict of interest is declared.

\section{Funding}

The project was conducted with funding from National Center for Strategic Research in Medical Education in Iran.

\section{Authors' contributions}

Leila Sadati and Zahra Nouri Khaneghah were involved in the conception and design of the work, analysis, and interpretation of data, drafting, and final approval of the manuscript. Rana Abjar, Fateme Edalat, Sahar Karami, and Mehdi Tayebi-Arasteh collected data and participated in drafting the manuscript. Pourya Kanani contributed to the data collection/analysis. All authors read and approved the final manuscript.

\section{Acknowledgments}

The researchers would like to thank the management of Nasr center of the ministry of health and medical education for all material and spiritual supports during the approval and implementation of this study. In addition, we would like to thank all students, preceptors, and the head of the operating room department of Alborz University of Medical Sciences for their collaboration and participation in this project.

\section{References:}

1. Hawkins RE, Welcher CM, Holmboe ES, Kirk LM, Norcini JJ, Simons KB, et al. Implementation of competency-based medical education: are we addressing the concerns and challenges? Medical education. 2015;49(11):1086-102.

2. Heeneman S, Driessen EW. The use of a portfolio in postgraduate medical education-reflect, assess and account, one for each or all in one? GMS journal for medical education. 2017;34(5).

3. McLean LD. Time to replace the classroom test with authentic measurement. Alberta Journal of Educational Research. 1990.

4. McEwen LA, Griffiths J, Schultz K. Developing and successfully implementing a competency-based portfolio assessment system in a postgraduate family medicine residency program. Academic 
Medicine. 2015;90(11):1515-26.

5. Yoo DM, Cho AR, Kim S. Development and validation of a portfolio assessment system for medical schools in Korea. Journal of educational evaluation for health professions. 2020;17.

6. Heeneman S, Driessen E, Durning SJ, Torre D. Use of an e-portfolio mapping tool: connecting experiences, analysis and action by learners. Perspectives on medical education. 2019;8(3):197200.

7. Scholz K, Tse C, Lithgow K. Unifying Experiences: Learner and Instructor Approaches and Reactions to ePortfolio Usage in Higher Education. International Journal of ePortfolio. 2017;7(2):139-50.

8. Nairn S, O'Brien E, Traynor V, Williams G, Chapple M, Johnson S. Student nurses' knowledge, skills and attitudes towards the use of portfolios in a school of nursing. Journal of clinical nursing. 2006;15(12):1509-20.

9. Hill TL. The portfolio as a summative assessment for the nursing student. Teaching and Learning in Nursing. 2012;7(4):140-5.

10. Tailor A, Dubrey S, Das S. Opinions of the ePortfolio and workplace-based assessments: a survey of core medical trainees and their supervisors. Clinical Medicine. 2014;14(5):510.

11. Fisher M, Hill A. Eportfolio implementation in a multiple campus university environment: academic preceptor continuous improvement. International Journal for Cross-Disciplinary Subjects in Education. 2017:3055-63.

12. Hall P, Byszewski A, Sutherland S, Stodel EJ. Developing a sustainable electronic portfolio (ePortfolio) program that fosters reflective practice and incorporates CanMEDS competencies into the undergraduate medical curriculum. Academic Medicine. 2012;87(6):744-51.

13. Gómez SS, Ostos EMC, Solano JMM, Salado TFH. An electronic portfolio for quantitative assessment of surgical skills in undergraduate medical education. BMC medical education. 2013;13(1):1-9.

14. Kirkpatrick D, Kirkpatrick J. Evaluating training programs: The four levels: Berrett-Koehler Publishers; 2006.

15. Ahmady S, Asayesh H, Aghaali M, Safaeipour R. A comparison of the effect of clinical evaluation by two methods of electronic portfolio and conventional on the level of students' satisfaction. Qom University of Medical Sciences Journal. 2016;9(12):41-9.

16. Lai C-Y, Wu C-C. Promoting nursing students' clinical learning through a mobile e-portfolio. CIN: Computers, Informatics, Nursing. 2016;34(11):535-43.

17. Vaghee S, Banezhad A, Karimi Moonaghi H, Soadatjo SA, Salarhaji A. The Effect of Applying Portfolio on the Level of Learning among Nursing Students in Clerkship of Psychiatry Ward. Future of Medical Education Journal. 2016;6(1):25-30.

18. Brown JO. Know thyself: The impact of portfolio development on adult learning. Adult Education Quarterly. 2002;52(3):228-45. 
19. Heidari T. The effect of Portfolio's evaluation on learning and satisfaction of midwifery students. Journal of Arak University of Medical Sciences. 2010;12(4):81-8.

20. L F, hazrati h, mohammadzadeh $\mathrm{m}, \mathrm{H} \mathrm{H}$. The Effect of Portfolio on Motivation and Academic Achievement of Students of Tabriz University of Medical Sciences. Military Caring Sciences. 2018;4(4):288 - 94. eng.

21. Bahreini M, Moattari M, Shahamat S, Dobaradaran S, Ravanipour M. Improvement of Iranian nurses' competence through professional portfolio: A quasi-experimental study. Nursing \& health sciences. 2013;15(1):51-7.

22. Asadi S, Latifi SM, Sheini-Jaberi P. Effects of clinical education and evaluation with portfolio method on nursing students' satisfaction: a clinical trial. Journal of clinical nursing and midwifery. 2014;3.

23. Kim HW, Park S, Ahn HY, Park E-J. The effects of an HPV education program by gender among Korean university students. Nurse education today. 2015;35(4):562-7.

24. Douglas ME, Peecksen S, Rogers J, Simmons M. College Students' Motivation and Confidence for ePortfolio Use. International Journal of ePortfolio. 2019;9(1):1-16.

25. Van Der Gulden R, Heeneman S, Kramer A, Laan R, Scherpbier-de Haan N, Thoonen B. How is selfregulated learning documented in e-portfolios of trainees? A content analysis. BMC medical education. 2020;20(1):1-13.

26. Bahreini M, Shahamat S, Moattari M, Akaberian S, Sharifi S, YAZDANKHAH FM. Development of reflective skills among nurses through portfolio: A qualitative study. 2012. 